\title{
APOPTOSE, NEUTRÓFILOS E O CIRURGIÃO
}

\author{
APOPTOSIS, NEUTROPHILS AND THE SURGEON
}

\author{
Fernando Antonio Campelo Spencer Netto, ACBC-PE ${ }^{1}$ \\ Edmundo Machado Ferraz, TCBC-PE ${ }^{2}$
}

\begin{abstract}
RESUMO: O estudo do processo de morte celular programada ganhou impulso a partir da demonstração da sua presença em células maduras não germinativas em 1971. A apoptose é um mecanismo vital normal, que acontece a todo o tempo nos organismos, permitindo a preservação da homeostase e renovação celular, possuindo características cito/histológicas próprias. Este trabalho faz uma revisão sumária de aspectos básicos da apoptose de interesse do cirurgião. São revistos dados da literatura referentes à apoptose no tocante às características cito/ histológicas e sua importância na ontogênese, homeostasia, patogênese, inflamação sistêmica, sepse abdominal e trauma. Alterações no processo de apoptose no embrião podem levar a malformações congênitas. No adulto, algumas doenças expressam-se por aumento (ex. isquemia miocárdica, Alzheimer etc.) ou diminuição nas taxas de apoptose (ex. câncer, doenças auto-imunes etc.). De particular interesse para o cirurgião, a elevação numérica dos neutrófilos que ocorre durante processos de inflamação sistêmica e trauma, deve-se à inibição da apoptose. A morte celular programada nos neutrófilos pode ser alterada por uma série de processos celulares (ex: adesão, transmigração etc.), substâncias endógenas e exógenas (ex: citocinas e lipopolissacarídeo), produzindo diferentes taxas de apoptose de acordo com a interação dos fatores. $\mathrm{O}$ aprofundamento no estudo da morte celular programada, com a possibilidade de sua modulação, a coloca como potencialmente aliada na terapêutica.
\end{abstract}

Descritores: Apoptose; Neutrófilos; Síndrome da resposta inflamatória sistêmica.

\section{INTRODUÇÃOO}

O desenvolvimento da biologia molecular tem levado ao reconhecimento e à melhor compreensão de alguns mecanismos biológicos, possibilitando sua utilização na prática clínica. O incremento do estudo da morte celular programada ou apoptose, processo biológico, necessário e essencial para o desenvolvimento e homeostase dos organismos, vem ajudando a explicar uma série de enfermidades. Desordens no mecanismo de morte celular programada, podem levar a doenças, seja por aumento de sobrevida nas células, denotando falha no sistema de indução da apoptose (ex.: câncer, doenças auto-imunes e infecções virais), ou no sentido inverso, onde observa-se a elevação das taxas de morte celular por ativação excessiva da apoptose (ex. isquemia miocárdica, cerebral, SIDA etc.). O aprofundamento do tema tem levado a tentativas de modulação do processo, com intuito terapêutico.

Nesta breve revisão, expõem-se os principais aspectos relacionados à apoptose, inclusive os que envolvem afecções de interesse cirúrgico e as interações com neutrófilos e a inflamação sistêmica.

1. Chefe da Emergência do Hospital Getúlio Vargas - Recife. Instrutor do ATLS. Mestre em Cirurgia.

2. Professor Titular das Disciplinas de Bases da Técnica Cirúrgica e Cirurgia Gastroenterológica da UFPE. Chefe do Serviço de Cirurgia Geral do Hospital das Clínicas da UFPE.

Recebido em 27/1/2000

Aceito para publicação em 25/7/2000

Trabalho realizado no Serviço de Cirurgia Geral do Hospital das Clínicas da Universidade Federal de Pernambuco UFPE. 


\section{HISTÓRICO}

Os achados histológicos da apoptose foram descritos pela primeira vez por Walther Flemming, em 1885 ao estudar folículos ovarianos maduros de mamíferos. Em 1914, Ludwig Graper, ao pesquisar células de endométrio propôs que este mecanismo seria oposto ao processo de mitose, e que estaria presente em todos os órgãos em que houvesse necessidade de eliminação de células. Suas observações não receberam a importância devida, passando-se algumas décadas sem estudos relevantes sobre o tema. Em 1950, Glucksmann, examinando embriões, verificou ser este um processo comum nesta fase de desenvolvimento, propondo ser esta uma forma especial de morte limitada a tecidos embrionários. Kerr, a partir de 1971, analisando o fígado de ratos submetidos à ligadura de segmentos dos vasos portais, demonstrou as mesmas alterações histológicas anteriormente descritas, desta vez em células não germinativas ou embrionárias, retomando os conceitos do início do século. A este mecanismo de morte celular, Kerr denominou apoptose. Esta palavra é de origem grega e refere-se a perda de pétalas ou folhas caindo no outono, numa alusão a uma perda aceitável, para uma posterior renovação. Desde então, um grande espectro de particularidades vem sendo estudado sobre fatores relacionados a este processo ${ }^{1,2}$.

\section{NECROSE E APOPTOSE}

Necrose e apoptose, processos de morte celular conhecidos atualmente, são desencadeados por estímulos diversos, sendo factível sua diferenciação, e conseqüente mensuração, por alterações específicas ocorridas no nível dos compartimentos celulares ${ }^{3,4,5}$.

A necrose, geralmente mediada por estímulos externos agressivos e não fisiológicos, como a hipóxia por exemplo, é um mecanismo passivo e patológico ${ }^{4}$. São achados morfológicos/bioquímicos característicos da necrose: a) perda da arquitetura do citoesqueleto de membrana celular e organelas, com balonização e formação de bolhas, culminando com ruptura e lançamento dos componentes citossólicos no meio extracelular, desencadeando resposta inflamatória tecidual que é um achado constante; b) perda da homeostasia iônica intracelular, com aumento das concentrações de sódio e de cálcio e queda das concentrações de potássio intracelular com alteração concomitante de permeabilidade a líquido; c) desequilíbrio oxidativo, com predomínio de agentes oxidantes; d) disfunção micotondrial levando à depleção dos níveis de ATP; e) ativação de hidrolases degradativas (proteases, fosfolipases e endonucleases) a níveis citossólico e lisossômico. O DNA nuclear sofre hidrólise de forma inespecífica ${ }^{2}$.

Devido à liberação de hidrolases e cininas no meio, há migração de células leucocitárias ao redor das células necróticas para a fagocitose, bem como edema e dilatação capilar. Esta resposta inflamatória leva de horas a dias para ocorrer, e leva à formação de cicatriz. A necrose ajuda a limitar a infecção, porém pode lesar extensamente o tecido normal adjacente ${ }^{3-6}$.
Apoptose, ou morte celular programada, é um processo vital normal que ocorre todo o tempo nos organismos, de forma ativa e fisiológica. As células, em resposta a estímulos externos ou inerentes à célula, perdem a aderência ao tecido adjacente e estruturas especializadas, como as microvilosidades. Formam-se bolhas citoplasmáticas e a cromatina nuclear condensa e fragmenta-se de forma regular, sendo envolta pela membrana nuclear. A célula perde líquido e divide-se em segmentos envolvidos pela membrana celular chamados corpos apoptóticos ${ }^{3-6}$. Todo o processo é mediado por vias intracelulares complexas, exigindo a produção de proteínas a partir do material gênico ${ }^{4}$, 7. Os corpos apoptóticos são fagocitados por macrófagos adjacentes sem sinais de inflamação local. É estimado que o processo dure cerca de duas horas desde as primeiras mudanças estruturais até a ingestão pelos fagócitos ${ }^{3-5}$.

A morte celular programada pode ser observada por microscopia ou eletroforese de DNA, uma vez que a fragmentação de DNA segue um padrão característico, sendo este último método qualitativo ${ }^{8}$.

A aferição das taxas de apoptose através da citometria de fluxo trouxe a possibilidade de sua quantificação, simplificando o processo. Através desta técnica, a morte celular programada pode ser detectada com o uso de corante nuclear, permitindo a quantificação através da identificação das células com DNA fragmentado (hipodiplóide) ${ }^{8-10}$ ou ainda pela verificação da fosfatidilserina na membrana celular, fosfolipídio que exterioriza-se precocemente na membrana celular de células em apoptose ${ }^{11,12}$.

\section{APOPTOSE, ONTOGÊNESE, HOMEOSTASIA E PATOGÊNESE}

A morte celular programada é essencial para o crescimento e desenvolvimento dos organismos. Embora o processo tenha sido documentado em células embriônicas desde 1950, ganhou impulso há cerca de 30 anos quando foi detectado em organismos maduros. Os estudos com o $\mathrm{Ca}$ enorhabditis elegans, um pequeno nematóide, foram de importância para o entendimento da entidade. Este verme maduro possui 1.090 células, perdendo precisamente 131 delas durante o processo de maturação ${ }^{3,5}$.

Todo o mecanismo de transformação no embrião humano, como o desaparecimento de membranas interdigitais, fendas faríngeas e tubulização do intestino deve-se à apoptose, sendo que a falha nestes processos pode levar a malformações como sindactilia, anomalias craniofaciais, estenose/atresia intestinal ${ }^{4,5}$.

A todo o momento, células estão morrendo devido à morte celular programada nos seres humanos a fim de garantir a homeostase. Queratinócitos iniciam a vida a partir de camadas profundas da pele, e entram em apoptose durante sua jornada às camadas superficiais onde descamam. Este sistema de migração e descamação leva cerca de 21 dias, podendo ser acelerado por exemplo por queimaduras solares, levando à morte de células mais profundas ${ }^{3,4}$.

No intestino, as células migram das criptas para o ápice das vilosidades, onde perdem o contato com a membrana basal e morrem, sendo perdidas no lúmen intestinal. De for- 
ma semelhante, as células endometriais são perdidas na menstruação. Nos casos expostos, evidencia-se a tentativa de equilíbrio entre a produção e morte celular, regulada por fatores tróficos da membrana basal ou hormonais ${ }^{3,4}$.

Durante o desenvolvimento do sistema imunológico, os linfócitos que reagem contra antígenos do hospedeiro são eliminados por apoptose, podendo haver a expressão clínica de doença auto-imune se não isto não ocorre de forma adequada $3,4,13,14$

Da mesma forma, células transformadas são induzidas à morte, evitando o aparecimento de neoplasias. O acúmulo de mutações em vários genes é necessário para que a célula exiba alterações fenotípicas características do câncer. Quando verifica-se a irreversibilidade da transformação, mecanismos de reparo são acionados, desencadeando a apoptose da célula modificada. Se por alguma falha esta seqüência de reparo não entra em ação, a célula continuará se multiplicando a despeito da inibição da replicação por contato ou falta de fatores de crescimento e originando metástases. Na maioria dos tumores sólidos em humanos, inclusive pulmão, cólon e mama, observa-se uma falha na expressão da proteína p53, que induz à morte celular programada. Neoplasias de cólon com alguma expressão desta proteína, têm melhor resposta à radio e quimioterapia do que aquelas em que não se evidencia o gene ${ }^{3,13,14}$.

A Bcl-2, outra proteína relacionada ao desenvolvimento de neoplasias, particularmente linfomas, onde encontra-se em produção excessiva, bloqueia os mecanismos de indução da apoptose ${ }^{3,4}$. O conhecimento de sua forma de ação pode levar à atuação específica, inclusive com a ajuda da engenharia genética, propiciando maior eficácia terapêutica.

A orquiectomia ou ooforectomia age na indução da apoptose de células, inclusive neoplásicas, que dependem de estímulo hormonal para seu crescimento ${ }^{13,14}$. A expressão excessiva da ciclooxigenase 2 é associada com a supressão da apoptose em câncer de cólon humano. O uso de antiinflamatórios não-hormonais ocasionou o retorno aos níveis normais de apoptose e a regressão de adenomas em pacientes com adenomatose familiar ${ }^{13}$.

Em contraste com as enfermidades anteriores, a morte excessiva pode ocorrer em eventos isquêmicos em cérebro e miocárdio. Nestas entidades, uma parte das células morre imediatamente por necrose, em decorrência da privação aguda de oxigênio e glicose, essenciais para os mecanismos básicos intracelulares. No período que se segue, a zona circunjacente pode morrer, a despeito de receber irrigação. Isto pode ocorrer por necrose, em virtude de lesão direta decorrente da reação inflamatória despertada, porém, a maioria é levada à apoptose ${ }^{3}$.

Correlacionando outras afecções do aparelho digestivo, a infecção gástrica pelo Helicobacter pylori causa liberação de nitrogênio endógeno reativo, que lesa o DNA e estimula a apoptose de células gástricas. O tratamento leva a uma diminuição das taxas de morte celular. A acalásia não chagásica está relacionada a uma perda de neurônios mioentéricos pelo mesmo mecanismo. Na colite ulcerativa, as células da cripta também são induzidas à morte celular. No fígado, uma série de doenças está relacionada à apoptose como as neoplasias e toxicidade por álcool e ou- tras substâncias. O álcool também está envolvido na indução da morte celular em células pancreáticas na pancreatite alcoólica ${ }^{3-6,14}$.

\section{APOPTOSE , INFLAMAÇÃO SISTÊMICA E SEPSE ABDOMINAL}

A regulação das taxas de morte celular programada em neutrófilos polimorfonucleares (PMN) é responsável por seu aumento numérico durante as infecções e posterior retorno aos valores basais ${ }^{5}$. O período de vida do neutrófilo está entre os mais curtos entre todas as células. Eles vivem menos do que um dia entre a liberação pela medula óssea e a morte por apoptose, sendo fagocitados por macrófagos do fígado ou baço ${ }^{15}$. In vitro, após $24 \mathrm{~h}$ em cultura, uma grande proporção de PMN extraído do sangue periférico ou tecidos inflamados exibe características celulares compatíveis com apoptose ${ }^{16}$. Neutrófilos apoptóticos perdem gradualmente as funções de mudança de formato e migração, reduzindo a resposta receptor dependente à degranulação, metabolismo oxidativo e fagocitose ${ }^{17}$.

A taxa de morte celular programada nos neutrófilos é muito sensível às condições ambientais. A exposição a componentes orgânicos e alguns processos celulares podem alterar a expressão da mesma nesta célula. Substâncias bacterianas como endotoxinas e algumas citocinas provocam uma diminuição na taxa de apoptose, aumentando a sobrevida e conseqüentemente o número dos neutrófilos circulantes na tentativa de fortalecer as defesas orgânicas ${ }^{18}$. Os neutrófilos inflamatórios perdem sua sensibilidade aos mecanismos de indução de apoptose e circulam por longos períodos ${ }^{5}$.

A adesão do PMN ao endotélio, um dos passos precoces na resposta inflamatória, mediado por receptores de membrana específicos (moléculas de adesão), modula funções efetoras no PMN como concentração de cálcio intracelular, estado do citoesqueleto, resposta aos agonistas da inflamação ${ }^{19-21}$. A adesão de PMN a diferentes superfícies leva a diferenças na regulação das taxas de morte celular programada, a depender da superfície. A adesão ao endotélio ativado com exposição prévia à interleucina-1 (Il-1), reduz as taxas de apoptose em relação à adesão ao endotélio não ativado, sendo este efeito revertido pela adição ao meio de anticorpos monoclonais contra a molécula de adesão intercelular-1 (ICAM-1) e contra a cadeia $b_{2}$ das integrinas leucocitárias ${ }^{20}$.

O processo de localização neutrofílica em resposta a um estímulo inflamatório é precoce, decorrendo da interação entre as moléculas de adesão dos polimorfonucleares (PMN) e seus contra-receptores no endotélio, seguidos da transmigração para o local da lesão ${ }^{21,22}$. Watson et al. demonstraram que o processo de transmigração pelo endotélio pode modular as taxas de apoptose ao induzir a migração em membrana em resposta a um quimiotático. Observaram que PMN não estimulados que migram aumentam a taxa de morte celular, enquanto que PMN prétratados com lipopolissacarídeo (LPS) apresentavam retardo na apoptose que era exacerbado com a migração através do endotélio ${ }^{23}$. 
O Fas, receptor de membrana tipo I, membro da família do TNF, expresso nos PMN e em uma série de células, quando ativado pelo seu anticorpo agonista ou ligante fisiológico (Fas ligand - FasL), leva à transdução do sinal para morte celular, sendo um mecanismo reportado de apoptose constitucional nos $\mathrm{PMN}^{24,25}$.

Estudando apoptose constitucional em PMN de voluntários sadios idosos, Tortorella et al. não observaram diferença estatisticamente significativa entre este grupo e de voluntários sadios jovens, seja na taxa de morte celular programada espontânea ou induzida por Fas- $\mathrm{L}^{26}$.

Watson et al. demonstraram, in vitro, um aumento dose-dependente das taxas de apoptose em PMN não ativados expostos ao anticorpo anti-Fas, resposta que não foi observada em PMN ativados previamente pela exposição ao LPS ou transmigração de membrana. Uma vez que o LPS induz o aumento de concentração intracelular de glutation, foi induzido o aumento da concentração do antioxidante no intracelular através do incremento da concentração no meio, observando diminuição nas taxas de morte celular programada dos PMN submetidos à anti-Fas ${ }^{25}$.

A exposição à prostaglandina $\mathrm{E}_{1}$ e $\mathrm{E}_{2}\left(\mathrm{PGE}_{1}\right.$ e $\left.\mathrm{PGE}_{2}\right)$, que modulam funções celulares em neutrófilos através do $\mathrm{AMP}_{\mathrm{c}}$, retarda a apoptose em PMN em cultura ${ }^{27}$.

Watson et al., estudando morte celular programada em PMN humanos ativados por LPS, observaram que o efeito inibidor da apoptose induzido pela endotoxina era superado pelos efeitos de indução da mesma do TNF-a, ingestão de $E$. coli e do choque térmico, atingindo a taxa de apoptose valores semelhantes ao de PMN não ativados. Desta forma, demonstrou que a taxa de morte celular programada é resultado da interação entre fatores inibidores e indutores, no qual poderia haver predomínio, exacerbação ou anulação dos efeitos isolados ${ }^{28}$.

Liles et al. observaram em experimento in vitro, em que submetiam PMN a culturas com glicocorticóides (dexametasona, prednisolona e hidrocortisona), que, ao contrário do efeito observado em linfócitos, houve redução na taxa de apoptose ${ }^{29}$.

Em Recife, Coutinho et al., em estudo conjunto com as Universidades de Aberdeen e Nottingham, ambas no Reino Unido, verificaram alterações no nível de mucosa e submucosa de intestino delgado em pacientes com sepse intra-abdominal. Observaram aumento da morte celular programada de plasmócitos e uma conseqüente redução na Ig A e Ig M, favorecendo a adesão e a translocação bacteriana ${ }^{30}$.

\section{APOPTOSE E TRAUMA}

No trauma, freqüentemente associam-se o choque hipovolêmico e a contaminação, sendo a síndrome da resposta inflamatória sistêmica (SRIS) e a sepse as principais causas de mortalidade tardia nestes pacientes ${ }^{31}$.

Neutrófilos de pacientes gravemente traumatizados demonstram inibição da taxa de morte celular programada, que permanece por três semanas ${ }^{32}$.

Pacientes queimados, submetidos a cirurgias eletivas de grande porte e com SRIS demonstraram diminuição nas taxas de apoptose. Plasma de portadores de SRIS inibem a expressão da morte celular programada em neutrófilos de doadores sadios ${ }^{33}$.

Ertel et al. observaram, em pacientes com trauma craniano e torácico, que o líquido cefalorraquidiano e o lavado broncoalveolar demonstram concentrações elevadas de GCSF. Quando incubados com PMN de doadores sadios, estes produziam inibição das taxas de apoptose que eram parcialmente revertidas quando as soluções eram tratadas previamente com anticorpo monoclonal contra G-CSF ${ }^{34}$.

Em estudo envolvendo choque hipovolêmico e ressuscitação em ratos, Deb et all. demonstraram aumento das taxas de apoptose em intestino delgado e fígado em animais ressuscitados com Ringer lactato (RL), enquanto não observou-se diferença entre os animais ressuscitados com SSH ou sangue total dos utilizados como controle ${ }^{35}$.

Spencer Netto et al., estudando, in vitro, PMN humanos submetidos à solução salina hipertônica, demonstraram um aumento das taxas de morte celular programada e que PMN previamente submetidos à SSH não apresentavam a queda nas taxas de apoptose ao serem expostos à endotoxina bacteriana ${ }^{36}$.

A despeito de saber-se que a apoptose pode ser modulada, com uma aceleração ou retardo em sua expressão, que esta regulação que pode ser efetuada por substâncias exógenas ou endógenas, por alguns processos celulares, e que há necessidade de ativação de vias intracelulares a fim de desencadear os mecanismos de produção protéica a partir de material cromossômico, ainda há muito a ser esclarecido sobre o assunto.

Os fenômenos que regem a reposta inflamatória são complexos e ainda mantêm-se incompletamente compreendidos pelos investigadores. É possível que o aprofundamento no estudo do comportamento da morte celular programada em neutrófilos traga contribuição para sua compreensão, permitindo interferir na expressão da mesma, modulando-a e com isso evitando uma série de efeitos indesejáveis observados na SRIS.

\begin{abstract}
Studies addressing programmed cellular death process as have increased since 1971, when their presence in nongerminatives mature cells were observed. Apoptosis is a normal vital process that always happens in organisms preserves homeostasis and allows cellular renovation, with proper morphologic characters. This article reviews the basic aspects about apoptosis that are interesting for surgeons read. Literature data regarding apoptosis are reviewed toward morphological aspects and their role in ontogenesis, homeostasis, pathogenesis, systemic
\end{abstract}


inflammatory syndrome, abdominal sepsis and trauma. Changes in apoptosis rates in the embryo could cause congenital malformations. In adults, some diseases present increases (ex. miocardic ischemia, Alzheimer's disease, etc.) or decreases in apoptosis rates (ex. cancer, autoimmunity, etc.). With particular interest to the surgeon, the numeric increase in the neutrophills during systemic inflammatory response or trauma, occur due to inhibition of apoptosis in these cells. The neutrophil's programmed cellular death can be changed for several cellular process (ex: adhesion, transmigration, etc.), endogenous and exogenous substances (ex: cytokines and endotoxin), producing different apoptosis' rates, depending on the interaction of agents.The apoptosis' study permits its modulation and potential benefits.

Key Words: Apoptosis; Neutrophils; Systemic response inflammatory syndrome.

\section{REFERÊNCIAS}

1. Majano G, Joris, I. Apoptosis, Oncosis and Necrosis. Am J Pathol 1995, 146:315.

2. Rosser BG, Gores GJ. Liver cell necrosis: cellular mechanisms and clinical implications. Gastroenterology 1995, 108:252-275.

3. Duke RC, Ojcius DM, Young JD. Cell suicide in health and disease. Sci Am 1996, 275:80-87.

4. Kuan N, Passaro Jr E. Apoptosis: programmed cell death. Arch Surg 1998, 133:773-775.

5. Marshall JC, Watson RW. Progammed Cell Death (apoptosis) and resolution of systemic inflammation. Surg Biol for the Clin 1997, 40:169-174.

6. Flora-filho R, Zilberstein B. Apoptosis: programmed cell death. Arq Bras Cir Dig 1996, 11:72-77.

7. Cox G, Austin RC. Dexamethasone-induced suppression of apoptosis in human neutrophils requires continous stimulation of new protein synthesis. J Leukoc Biol 1997, 61:224-230.

8. Mccloskey TW, Oyaizu N, Coronesi M et al. Use a flow cytometric assay to quantitative apoptosis in human lymphocytes. Clin Immunol Immunopathol 1994, 71:14-18

9. Nicoletti I, Migliorati G, Pagliacci MC, et al. A rapid and simple method for measuring thymocyte apoptosis by propidium iodide stainig and flow cytometry. J Immunol Methods 1991, 139:271-276.

10. Telford WG, King LE, Fraker PJ. Comparative evaluation of several DNA binding dyes in the detection of apoptosis-associated chromatin degradation by flow cytometry. Cytometry 1992, 13:137-143.

11. Homburg CHE, Haas M, Borne AG, et al. Human neutrophil lose their surface FcgRIII and acquire annexin V binding sites during apoptosis in vitro. Blood 1995, 85:532-540.

12. Vermes I, Haanen C, Steffens-nakken H, et al. A novel assay for apoptosis flow cytometric detection of phosphatidylserine expression on early apoptotic cells using fluorescein labelled Annexin V. J. Immunol Meth 1995, 184:39-51.

13. Thate U, Dahanukar S. Apoptosis: clinical relevance and pharmacological manipulation. Drugs 1997, 54:511534.

14. Thompson CB. Apoptosis in the pathogenesis and treatment of disease. Science 1995, 167:1456-1462.
15. Haslett C. Resolution of acute inflammation and the role of apoptosis in the tissue fate of granulocytes [editorial]. Clin Sci 1992, 83:639-648.

16. Savill JS, Wyllie AH, Henson JE et al. Macrophage phagocytosis of aging neutrophils in inflammation. J Clin Invest 1989, 83:865-875.

17. Whyte MKB, Meagher LC, Macdermot J et al. Impairment of function in aging neutrophils is associated with apoptosis. J Immunol 1993, 150:5124-5134.

18. Colotta F, Re F, Polentarutti N et al. Modulation of granulocyte survival and programmed cell death by cytokines and bacterial products. Blood 1992, 80:20122020.

19. Chacon-Cruz E, Oelberg DG, Davis P et al. Membrane depolarization and depletion of intracellular calcium stores are associated with delay of apoptosis in human neutrophils. J Leukoc Biol 1998, 64:759-766.

20. Ginis I, Faller DV. Protection form apoptosis in human neutrophil is determined by the surface of adhesion. Am J Physiol 1997, 272:c295-c309.

21. Worthen GS, Downey GP. Mechanisms of neutrophil mediated injury. IN: Acute respiratory distress in adults. Chapman \& Hall, London, 1993; 99-114.

22. Ward PA, Lentsch $\mathrm{AB}$. The acute inflammatory response and its regulation. Arch Surg 1999, 134:666-669.

23. Watson WG, Rotstein O, Nathens AB et al. Neutrophil apoptosis is modulated by endothelial transmigration and adhesion molecule engagement. J Immunol 1997, 158:945-953.

24. Liles WC, Kiener PA, Ledbetter JA et al. Differential expression of Fas (CD95) and Fas ligand on normal human phagocytes: implications for the regulation of apoptosis in neutrophils. J Exp Med 1996, 184:429440.

25. Watson WG, Rotstein O, Jimenez $\mathrm{M}$ et al. Augmented intracellular glutathione inhibits Fas-triggered apoptosis of activated human neutrophils. Blood 1997, 89:4175-4181.

26. Tortorella C, Piazzolla G, Spaccavento F et al. Spontaneus and Fas-induced apoptotic cell death in aged neutrophils. J Clin Immunol 1998, 18:321-329.

27. Walker Bam, Rocchini C, Boone RH et al. Adenosine $A_{2 a}$ receptor activation delays apoptosis in human neutrophils. J Immunol 1997, 158:2926-2931.

28. Watson RWG, Redmond HP, Wang JH et al. Bacterial ingestion, tumor necrosis factor-alpha, and heat induce programmed cell death in activated neutrophils. Shock 1996, 5:46-51.

29. Liles C, Dale DC, Klebanoff SJ. Glucocorticoids inhibit apoptosis of human neutrophils. Blood 1995, 86:31813188 . 
30. Coutinho HB, Robalinho TI, Coutinho VB et al. Intra-abdominal sepsis: an immunocitochemical study of the small intestine mucosa. J Clin Pathol 1997, 50:294-298.

31. American College of Surgeons Commitee on Trauma. Advanced trauma and life support - Instructor course manual. Chicago: American College of Surgeons, p. $990,1997$.

32. Ogura H, Tanaka H, Koh T et al. Priming, second-hit priming, and apoptosis in leucocytes from trauma patients. J Trauma 1999, 46:774-783.

33. Jimenez MF, Watson RW, Parodo J et al. Dysregulated expression of neutrophil apoptosis in the systemic inflammatory response syndrome. Arch Surg 1997, 132:1263-1269.

34. Ertel W, Keel M, Buergi U, et al. Granulocyte colony-stimulating factor inhibts neutrophil apoptosis at the local site after severe head and thoracic injury. J Trauma 1999, 46:784-793.

35. Deb S, Martin B, Sun L et al. Resuscitation with lactated ringer's solution in rats with hemorrhagic shock induces immediate apoptosis. J Trauma 1999, 46:582589.
36. Spencer Netto Fac, Rizoli Sb, Marshall, et al. Estudo da taxa de apoptose em neutrófilos humanos expostos a solução salina hipertônica e lipopolissacarídeo. Rev Med HU-USP 2000, 10(1) - aceito para publicação.

Endereço para correspondência:

Dr. Edmundo Machado Ferraz

Rua Dom Sebastião Leme, 171/2501

52011-160 - Recife-PE

E-mail: kummer@netpe.com.br 